\title{
Gestão, Educação e Sustentabilidade
}

\section{EDITORIAL}

A nova edição da Revista de Ciências Humanas da Universidade de Taubaté reúne um elenco de artigos que traz temáticas emergentes, e também emergenciais, voltadas para a melhoria da qualidade de vida, relacionados à gestão, educação e sustentabilidade. Por meio da discussão da problemática ambiental em uma perspectiva de rede esse número da revista visa contribuir para a geração de uma cultura da percepção do ambiente e da sociedade, no amplo contexto da educação ambiental e da construção de sociedades sustentáveis.

Você, caro leitor, poderá conferir doze artigos com temáticas diversas, mas convergentes no retrato e na análise da sociedade contemporânea tratando desde propostas para geração de renda por meio da agricultura familiar, da educação ambiental, educação do campo, letramento cientifico, aprendizagem baseada em projetos até programas de qualidade de vida no trabalho, resultado de pesquisas e reflexões sobre a práxis nas suas dimensões socioculturais e ambientais.

O artigo de Marta Gouveia de Oliveira Rovai intitulado 'Educação para a diversidade de gênero e sexualidade: refletindo sobre práticas e discursos' objetiva apresentar uma breve reflexão sobre as discussões que envolvem as questões de gênero e sexualidade, sob a perspectiva das identidades e do protagonismo na defesa dos direitos, do feminismo e do movimento LGBT. O trabalho sobre a feira-livre como importante mercado para a agricultura familiar em Conceição do Mato Dentro (MG) analisa a dinâmica da feira como espaço de socialização, identidade regional e cultural e também de articulação política. O professor Carlos Alberto Máximo Pimenta da Universidade Federal de Itajubá, (UNIFEI) e suas orientandas Samanta Borges Pereira, Gabriela Belleze e Viviane Guimarães Pereira fazem um relato de experiência sobre os encontros do projeto de extensão executado na Universidade sob o nome 'Cine \& Prosa' no artigo 'Outras facetas do desenvolvimento: o uso de documentários na crítica ao modelo de desenvolvimento competitivo global'. Ricardo e Renato Santos David fazem um estudo de como as propostas trazidas nos PCN são abordadas pelos professores de Língua Portuguesa em 'Formação de Professores no Ensino de Língua Materna: Língua Portuguesa, Temas Transversais e Formação para Cidadania'. Neimar Juliano Albano da Silva, Danielle Silva de Novais Teixeira, Fabiana Barbosa de Jesus e Magda dos Santos Cardoso do Programa de Pós-Graduação em Projetos Educacionais de Ciências da Escola de Engenharia de Lorena, EEL, Universidade de São Paulo, USP, SP contextualizam o ensino de matemática na contemporaneidade ao proporem a criação de protótipos do espaço físico de um Laboratório de Ensino de Matemática (LEM). O 'Estudo diferenciado da coleta seletiva por alunos do ensino fundamental II', de Karina Ferreira Alves, Daniel Muniz de Souza e Paulo Rogério da Silva do mesmo Programa de mestrado da Escola de Engenharia de Lorena, EEL/USP discutiu a experiência de os alunos de uma turma do 70 ano de uma escola pública da cidade de Piquete/ SP no debate sobre a importância do lixo que é descartado na escola e seus impactos no meio ambiente. No artigo da doutoranda do Programa de Pós-Graduação em Ciência, Tecnologia e Sociedade pela UFSCar, Kemilly Bianca de Mello e de seu orientador Wilson José Alves Pedro, intitulado 'Gestão de Programas de Qualidade de Vida no trabalho em Instituições Públicas de Ensino Superior' poderemos saber mais sobre os Programas de Qualidade de Vida no Trabalho (PQVT) por meio da análise de três instituições públicas de ensino superior localizadas no interior do estado de São Paulo. Já Adriana Nascimento Figueira Gavazzi, Ana Luiza Lopes Sinieghi, Jean Marcel Capuzzi, Leonardo de Melo Souza investigam se há a possibilidade de inserir o processo de letramento científico no 5o ano do Ensino Fundamental por meio do artigo 'Uso 
do robô escova para a iniciação de crianças do 50 ano do ensino fundamental no letramento científico'. A professora doutora Alexandra Magna Rodrigues, e sua orientada Paula do Valle do Programa de mestrado de Desenvolvimento Humano da Universidade de Taubaté analisam as representações sociais de licenciandos em educação do campo residentes em uma zona rural sobre alimento orgânico no estudo 'Representações Sociais sobre Alimentos Orgânicos para Jovens do Campo'. Em os 'Trabalhadores do centro de referência especializado em assistência social: dificuldades vividas no cotidiano profissional', de Camila da Silva Lopes e da professora doutora Elisa Maria Andrade Brisola do mesmo Programa de mestrado, investiga os principais motivos de sofrimento dos trabalhadores que atuam nos Centros de Referência Especializados de Assistência Social (CREAS) em um município do Vale do Paraíba. No trabalho 'Destino do Resíduo Orgânico do Lar Escola Santa Verônica: como tornar restos alimentares em adubo orgânico através da técnica de compostagem', de Andreia Moura Casagrande, Hélio Valdemar Damião Freire, Lidiane de Melo Souza Moura e Luciene Monteiro Pimentel Quintas, apresenta a compostagem como estratégia ecológica no tratamento de resíduos orgânicos do Lar Escola Santa Verônica, situada no município de Taubaté-SP. Como afirmam os autores Luccas Santin Padilha, Matias Trevisol, Eliane Salete Filippim, a aprendizagem social para sustentabilidade tem emergido como uma abordagem mista para a resolução de problemas ambientais e sociais complexos é essa discussão atual que encontramos em seu trabalho 'A sustentabilidade da infância a vida adulta: a aprendizagem por meio da história de vida'.

Com essa visão completa e complexa da sociedade contemporânea esperamos contribuir com sua reflexão e aprofundamento teórico.

Boa leitura a todos!

\section{Juliana Marcondes Bussolotti}

